\title{
Towards sustainable waste management through structural testing of rice straw bale cement plasters
}

\author{
G. L. Garas ${ }^{1}$, M. E. Allam ${ }^{2}$ \& A. Ragab ${ }^{3}$ \\ ${ }^{1}$ Construction Management, National Research Centre, Cairo, Egypt \\ ${ }^{2}$ Materials Testing, National Research Centre, Cairo, Egypt \\ ${ }^{3}$ Material Testing Department, Cairo University, Egypt
}

\begin{abstract}
Over the past ten years burning rice straw has become a tragic environmental event that produces black clouds of smoke, the cause of a high degree of pollution, especially to the population of Cairo.

Using rice straw bales (RSB) in construction is a pioneering step in Egypt to solve this uncontrolled environmental problem. Although this technique has been shown to be strong and durable throughout the world in both load-bearing and post-and-beam structures, it is not yet a well acquainted technique in Egypt.

This research is a part of an ongoing global project that aims to test and demonstrate the use of straw bales as a building unit. This preliminary step is aimed at providing a baseline for establishing an appropriate addition to the Egyptian Building Codes using this non-traditional, sustainable, environmentally friendly building unit.

This paper aims to test the compression strength, modulus of elasticity and modulus of rupture of some Portland cement and lime plaster mixes. The results of this stage of research are intended to recommend the most appropriate cement plaster mix to be applied on the straw bale walls with respect to the structural behaviour. A comparison between the results of those tests and others reported in some previous published literature will also be discussed in this paper.
\end{abstract}

Keywords: environmental pollution, black cloud, rice straw bales, cement plaster tests. 


\section{Introduction}

Although rice has been cultivated in Egypt for a long time, the burning of rice straw, which remains after the grain is harvested, has become a major problem today because of the recent liberalization of government policies for crop cultivation. This has led to a significant increase in rice production because rice is now considered by farmers to be a lucrative crop. Rice straw is utilized in several industries in Egypt such as paper production, animal bedding and landscaping. The largest Egyptian paper factory uses about $5-7 \%$ of the available rice straw (3.6 million tons-according to the Egyptian Agricultural Ministry) in the production of paper.

The black cloud, which first appeared over Cairo in autumn of 1999, is becoming an annual environmental tragedy. One of its main causes, together with the existing pollution due to exhaust fumes and industrial emissions, is the illegal and uncontrolled burning of rice straw. Thermal inversions and poor air circulation during autumn causes the pollutants to remain in the air, close to the surface of the earth without dissipating, therefore blocking sunlight, forming the black cloud, and causing respiratory difficulties and other adverse health consequences in the Cairo populace.

Despite the environmental, health, and financial benefits, green building technologies have been slow to penetrate the mainstream of the construction industry in Egypt.

This research is a part of an ongoing global project that aims to test and demonstrate the use of rice straw bales (an agricultural waste) as a sustainable environmental friendly building unit. The study also combines major sources of environmental pollution such as wastes generated through the cement manufacturing industry as well as making use of steel cutlets, which are sold at the end of huge projects as residues. The project concerns the impediments to the adoption of "green" construction technologies. This preliminary step is aimed to provide a baseline for establishing an appropriate addition to the Egyptian Building Codes using this non-traditional building unit.

Very little research work was addressed in Egypt in the field of using straw bales in construction. The area of research covered the use of grinned straw in the concrete mix, while the direct use of straw bales as a building unit was not addressed.

Straw bale walls for houses have been used since the introduction of the mechanical baler in the early 1900's. Although straw bale houses were popular for a short while in a local area of Nebraska, they lost favour for nearly half a century. There has recently been a rebirth in straw bale construction and considerable interest. In many cases the interest stems from the highly insulating, simple, and sustainable nature of straw bale walls. The classic and time-proven straw bale wall assembly consists of straw bales with 25 to $50 \mathrm{~mm}$ thick mineral based stucco skins applied directly to both faces of the straw bale. The stucco skin of modern SB buildings is often made of steel mesh reinforced cement stucco skins applied directly to the straw bales. This coating provides a finish, a 
weather barrier, an air barrier, fire protection, rodent and insect control, and some structural properties (Straube [1]).

Over the past hundred years, plastered straw bale construction has shown itself to be strong and durable in both load-bearing and post-and-beam structures. In load-bearing straw bale systems, the relatively strong, stiff plaster plays a significant role as it works together with the ductile straw bale core to function as a stress skin panel, resisting compressive, in-plane and out-of plane loading. In post-and-beam straw bale systems with properly detailed connections, the plaster can act as a shear wall, resisting in-plane lateral loads. The final strength of these wall systems depends both on plasters and straw bales. Plasters serve many functions in a wall system.

They:

- Protect the underlying surface

- Permit or prevent the migration of vapour or liquid moisture

- Prevent the migration of air currents

- Carry structural loads

But before we can understand, analyse and model the structural performance of plastered straw bale walls, we must test and understand its elements-straw bales and plasters. The following tests begin to show the basic structural capacity of a variety of plasters.

Plasters are composed of a binder (e.g. clay, cement, lime) and fillers (sand, aggregate, fiber, etc). Plasters can be divided into two main categories:

- Those with a binder that undergoes a chemical reaction (such as cement, lime, or gypsum).

- Those with a binder that does not react chemically (such as clay). Lerner et al [2]

\section{Plaster/stucco skins}

Stucco or exterior plaster, defined as a hardened mix of fine aggregate and inorganic binders, is a highly desirable finish for walls and ceilings. In structural terms, cement, lime, gypsum, and clay-based plasters form a continuum from strong to weak and from brittle to ductile respectively.

Cement-based plasters are very strong and resistant to erosion, but often crack near openings (windows, doors, etc.) and corners because they are very brittle when compared to the straw bale wall core. Clay-based plasters are weaker and erode easily, but their relative ductility makes them a better structural match with straw bale walls.

Stucco that uses sand aggregate and cement binders is and has been widely used throughout the world for many years. In modern times, the stucco skin is often made of steel mesh reinforced cement stucco skins applied directly to the straw bales. The stucco used in straw bale walls can range from high-strength gunite or shotcrete to cement-lime mixtures to earth-based plasters with and without lime or cement stabilizers (Straube [1]). 


\section{Portland cement-lime plaster mixes}

The Portland cement-lime mixes vary widely according to the constituents of the parts of Portland cement, lime and sand, with just enough water added to produce a workable mix for hand plastering. These mixes produce a "Portland cement-lime plaster" which gains significant strength over the years as the calcium hydroxide hydrates to produce a stronger compound called calcium carbonate. Common practice describes stucco mixes as a volumetric ratio in the form $\mathrm{C}: \mathrm{L}: \mathrm{S}$, where $\mathrm{C}$ is the cement component, $\mathrm{L}$ is the lime component, and $\mathrm{S}$ is the sand component. In many straw bale buildings typical stucco mixes are 1:3 cement stucco or 1:1:6 cement-lime stucco (Straube [1]).

However, previous literature has addressed the structural behaviour of some basic mixes which will be considered as references in this study. The samples tested included:
A. 1:3 Cement: Sand
B. 1:1:6 Cement: Lime: Sand
C. 1:2:9 Cement: Lime: Sand
D. 1:3 Lime: Sand

The literature varied in the curing period left for the cement: lime plasters to gain its compressive strength (age of applied plaster).

Zhang [3] conducted his tests on SB plastered walls leaving two weeks between each cement coat with thickness averaged $40 \mathrm{~mm}$, while Mar [4] mentioned that plasters were cured for at least one month with $38 \mathrm{~mm}$ plaster skins. Dreger [5] rendered with a cement/lime/sand plaster in relative proportions $1: 1: 4$, in two coats separated by two days, and cured about seven days. This very short cure time was expected to bring a high lime plaster, at best, to half its ultimate strength, but as events transpired the ultimate reported test loads were limited by the loading mechanisms, not the soft plaster.

This paper will present the results of testing a variety of the basic cement: lime plaster mixes cured at 28 days compared to the results of a study conducted by Lerner \& Donahue [2] on a similar group of samples that were tested at 18,29, and 57 days.

\section{Materials specifications}

\subsection{Materials specifications}

All the materials used in this research were local materials. The properties of these materials were determined according to the Egyptian Standard Specifications and the recommended code of practice. Sand (fine aggregates) used in the concrete mix is siliceous sand from Pyramid quarries, Giza. The cement used was Helwan Ordinary Portland cement (OPC), and the lime was brought from the local market. Water used in mixing and curing concrete is in accordance to ASTM C 94 (1993) specifications. The temperature of mixing water was maintained between $20-30 \mathrm{C}$. The water (cement + lime) ratio $(\mathrm{w} / \mathrm{c})$ for the samples was 0.5 by weight for all the mixes in this study. 


\subsection{Plaster specimens preparation}

The plaster mixes were batched in rotating power-driven resolving mixer of 100 litres capacity according to the ASTM specifications (ASTM C192).

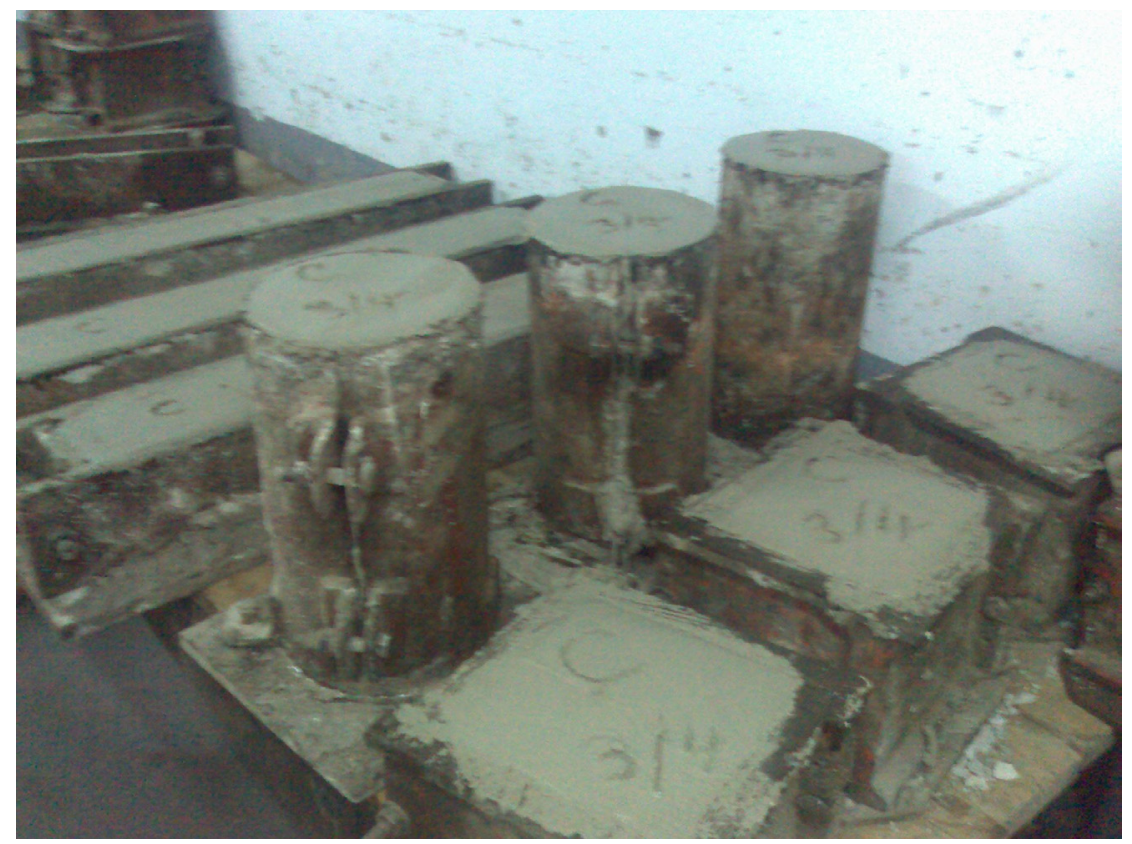

Figure 1: $\quad$ Samples after pouring.

Specimens for compression, modulus of rupture and modulus of elasticity testing for mixes A, B, C and D were cast as triplicates i.e. 18 at a time/ day for every two mixes and the average of each triplicate was calculated. The fresh mortar was placed in the molds tapped with a small spatula for 25 times, and then put on a vibratory (shaking) table for 2 minutes fig. 1 . The mixes then were kept in the molds for 24 hours. After 24 hours of casting, specimens were removed from the molds and cured in water tanks until the test time. The curing scheme is similar to the common practice in the Egyptian construction industry. The workability and consistency of the stucco mixes were measured using the slump cone test ASTM C143-89a, which was recorded in cm. After the slump test was completed, the specimen molds were oiled and placed on a levelled surface to be filled with the concrete mixture. The specimens were cast in accordance to ASTM C192-88. Plastic sheets were used to cover the specimens, to prevent the water from evaporating. After 24 hours, the specimens were striped from their respective molds and placed in water to cure for 28 days. 


\section{Structural tests}

\subsection{Compression test}

\subsubsection{Intent}

Compressive strength testing for all mixes (mixes A through D) was carried out on a 200 ton Tinuis Olsen machine model CMH 289 Controller in the material laboratory, Faculty of Engineering, Cairo University. The strength of stucco specimens at each test was represented by the average of three specimens as stated before. The method given in ASTM C39 (1990) was followed to test the concrete specimens.

\subsubsection{Test protocol}

Compression testing of all specimens was standard cubes $7.5 * 7.5 * 7.5 \mathrm{~cm}$, all of which were cured in water until testing. From each mixture produced, three specimens were tested for compression after 28 days.

\subsubsection{Test results and discussion}

The results of compression testing for all mixes are summarized in table 1 . The 4 mixes showed great variation in their compression strength values as plotted in fig 2. In the absence of cement, mix D showed very low values while the strength increased gradually by decreasing the lime content and using a steady proportion of cement. The highest compression strength reached about $281.5 \mathrm{Kg} / \mathrm{cm}^{2}$ for the mix with cement and sand 1:3 without any lime. The results of mix B with proportions 1:1:6 showed a value of about $150 \mathrm{Kg} / \mathrm{cm}^{2}$. This value is very high compared to the AME Portland cement-lime plaster for the same mix that was tested for various ages (18-29-57days). In the AME study the authors expected that the use of non-type $\mathrm{S}$ lime (where all the lime and other oxides are completely hydrated in a special double hydration process under optimal pressure and temperature conditions) in their mix was the reason of low strength compared to the expected values of $35-42 \mathrm{Kg} / \mathrm{cm}^{2}$ for plaster with type $\mathrm{S}$ lime. It should be noted that the AME study results were presented in psi, and a conversion of units to $\mathrm{Kg} / \mathrm{cm}^{2}$ was made to allow for comparison.

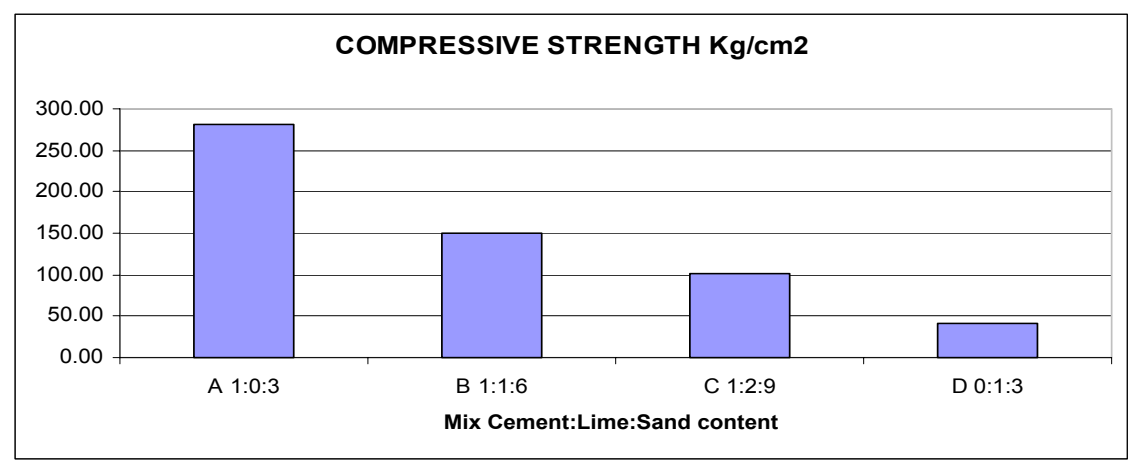

Figure 2: $\quad$ Average compressive strength of 4 mixes. 
Table 1: $\quad$ Compressive strength tests.

Sample dimensions are: $7 * 7 * 7 \mathrm{~cm}^{3}$

All Units are in $\mathrm{Kg} \& \mathrm{~cm}$. Age of Samples 28 days

\begin{tabular}{|c|c|c|c|}
\hline Sample & Ultimate load $(\mathrm{Kg})$ & $\begin{array}{c}\text { Ultimate Stress } \\
\left(\mathrm{Kg} / \mathrm{cm}^{2}\right)\end{array}$ & Avg. Stress $\left(\mathrm{Kg} / \mathrm{cm}^{2)}\right.$ \\
\hline \hline A-1 & 14847 & 303 & \\
\hline A-2 & 13144 & 268 & \\
\hline A-3 & 13388 & 273 & 281.49 \\
\hline & & & \\
\hline B-1 & 8004 & 163 & \\
\hline B-2 & 7301 & 149 & 149.56 \\
\hline B-3 & 6680 & 136 & \\
\hline & & & 100.44 \\
\hline C-1 & 5109 & 104 & \\
\hline C-2 & 4946 & 101 & \\
\hline C-3 & 4711 & 96 & \\
\hline & & & \\
\hline D-1 & 1621 & 33 & \\
\hline D-2 & 2254 & 46 & \\
\hline D-3 & 2274 & 46 & \\
\hline & & & \\
\hline
\end{tabular}

Table 2: $\quad$ AME compression tests cited in Lerner and Donahue [2].

\begin{tabular}{|c|c|c|c|c|c|c|}
\hline \multicolumn{4}{|c|}{ AME- Compressive Strength Tests } & \multicolumn{3}{|c|}{ PCL=Portland cement-lime plaster } \\
\hline Sample & $\begin{array}{c}\text { Age } \\
\text { (days) }\end{array}$ & Area & $\begin{array}{l}\text { Ultimate } \\
\text { Load }\end{array}$ & $\begin{array}{c}\text { Ultimate } \\
\text { Stress } \\
\text { (PSI) }\end{array}$ & $\begin{array}{c}\text { Ultimate } \\
\text { Stress } \\
\left(\mathrm{kg} / \mathrm{cm}^{2}\right)\end{array}$ & $\begin{array}{c}\text { Avg Ult. } \\
\text { Stress } \\
\mathrm{Kg} / \mathrm{cm}^{2}\end{array}$ \\
\hline PCL1 & 18 & 4 & 990 & 248 & 17.4 & \\
\hline PCL2 & 18 & 4 & 975 & 244 & 17.2 & \\
\hline PCL3 & 18 & 4 & 1200 & 300 & 21.1 & \\
\hline PCL4 & 18 & 4 & 1380 & 345 & 24.3 & 20 \\
\hline PCL5 & 29 & 4 & 1200 & 300 & 21.1 & \\
\hline PCL6 & 29 & 4 & 1020 & 255 & 17.9 & \\
\hline PCL7 & 29 & 4 & 1200 & 300 & 21.1 & \\
\hline PCL8 & 29 & 4 & 1170 & 293 & 20.6 & 20.2 \\
\hline PCL9 & 57 & 4.1 & 930 & 227 & 16.0 & \\
\hline PCL10 & 57 & 4.1 & 1200 & 293 & 20.6 & \\
\hline PCL11 & 57 & 4.1 & 1060 & 259 & 18.2 & \\
\hline PCL12 & 57 & 4.3 & 1280 & 298 & 21.0 & 18.8 \\
\hline
\end{tabular}




\subsection{Modulus of rupture test}

\subsubsection{Intent and protocol}

Modulus of rupture (MOR) testing of $10 * 10 * 70 \mathrm{~cm}$ samples was conducted according to ASTM C293 Standard test method for flexural strength of concrete using a calibrated machine testing machine (applied on a simple beam with two loading points at a span of $60 \mathrm{~cm}$ ) as shown in fig 3. The results for each group of beams were the average of three beams. Samples of all mixes were cured and tested at 28 days. The modulus of elasticity is calculated using the formula $\mathrm{R}=$ $\mathrm{PL} / \mathrm{bd}^{2}$ where

$\mathrm{R}$ is the modulus of rupture in $\mathrm{Kg} / \mathrm{cm}^{2}$

$\mathrm{P}$ is the maximum applied load $\mathrm{Kg}$

$\mathrm{L}$ is the span length, $60 \mathrm{~cm}$

$\mathrm{b}$ is the average width of beam, $10 \mathrm{~cm}$

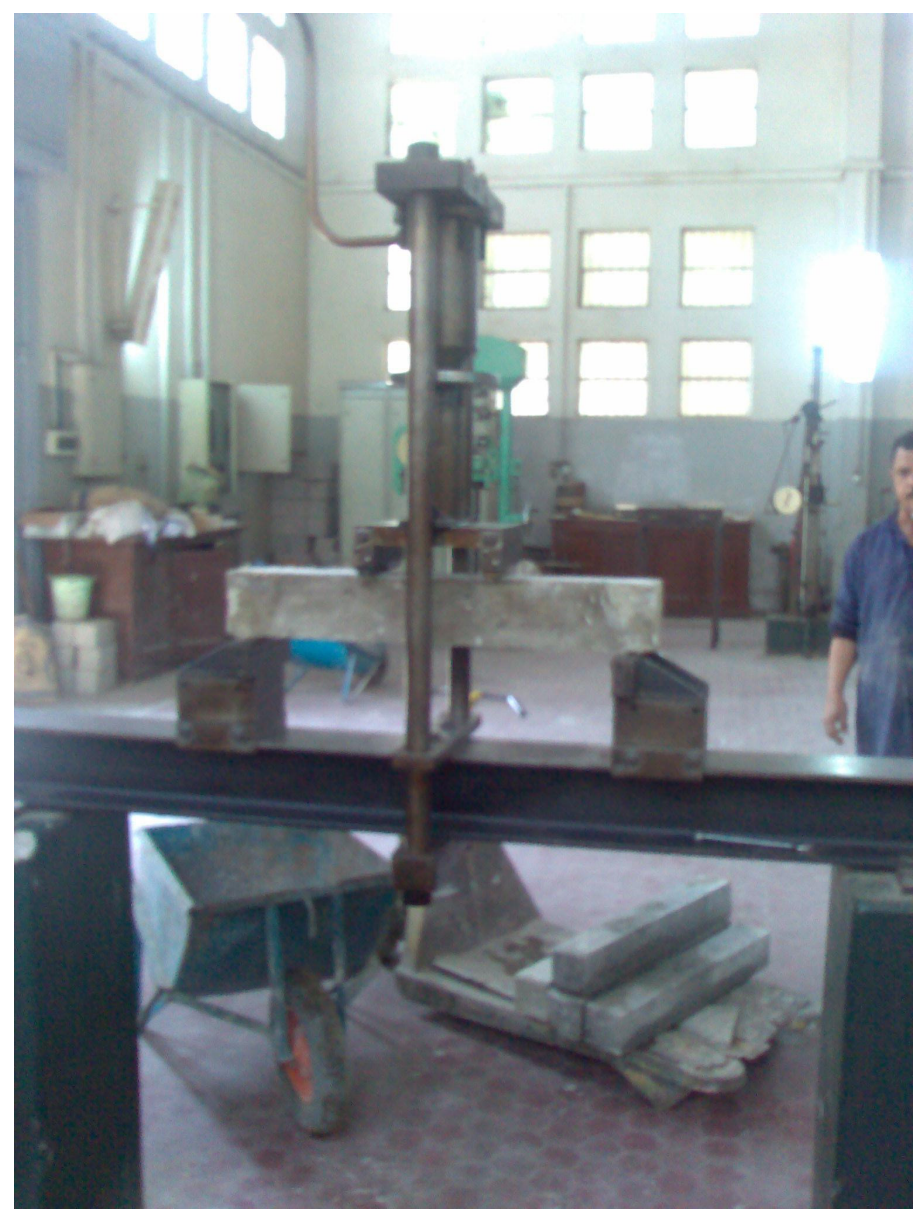

Figure 3: Modulus of rupture test. 


\subsubsection{Results and discussion of MOR tests}

The results in fig 4 indicate a strong correlation between increased cement content and the MOR values. Mix A without any lime content showed a MOR $57.66 \mathrm{~kg} / \mathrm{cm}^{2}$ almost double the result of Mix B with a proportion of cement equals to the proportion of lime. The average result of mix B with proportions 1:1:6 was $29.3 \mathrm{Kg} / \mathrm{cm}^{2}$ indicated great variance compared to the MOR results of the AME study $14.34 \mathrm{Kg} / \mathrm{cm}^{2}$ conducted by Lerner \& Donahue [2] for the same mix that was tested at 57 days. By increasing the lime content in mixes $\mathrm{C}$ and $\mathrm{D}$ the MOR decreased to 19.04 and $7.35 \mathrm{Kg} / \mathrm{cm} 2$ respectively.

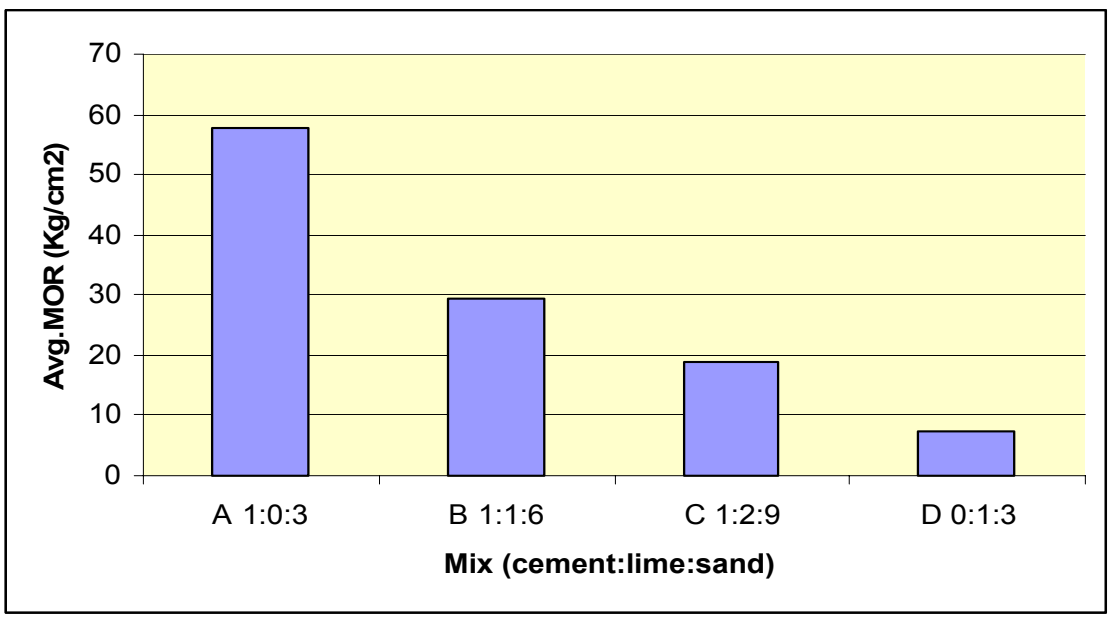

Figure 4: Average MOR test results.

\subsection{Modulus of elasticity test}

\subsubsection{Intent and protocol}

Modulus of elasticity (MOE) tests are conducted on all mixes using cylinders of $15 \mathrm{~cm}$ diameter and $30 \mathrm{~cm}$ height. This test was done using a 200 ton Tinuis Olsen machine model CMH 289 Controller in the material laboratory, Faculty of Engineering, Cairo University. The modulus of elasticity, as defined in ASTM $\mathrm{C} 469$, is the linear portion of the stress strain curve and is calculated according to the following formula: $\mathrm{M}=(\Delta \mathrm{P} / \mathrm{A}) / \Delta \mathrm{L} /$ Lo where

$\mathrm{M}$ is the modulus of elasticity

$\mathrm{N} / \mathrm{m}^{2}$ is the area in $\mathrm{m}^{2}$

$\Delta \mathrm{P}$ is $\mathrm{P} 2-\mathrm{P} 1$ in $\mathrm{N}$

$\Delta \mathrm{L}$ is $\mathrm{L} 2-\mathrm{L} 1$ in $\mathrm{m} \mathrm{Lo}=0.30 \mathrm{~m}$

$\mathrm{P} 1$ and $\mathrm{L} 1$ measured at 0.00005 strain

P2 and L2 measured at 0.40 of the ultimate load 


\subsubsection{Results and discussion of MOE tests}

The average Portland cement-lime plaster MOE results of mixes A, B, C, \& D were $42507.6,31804.28, \quad 16106.01$ and $5096.84 \mathrm{Kg} / \mathrm{cm}^{2}$ respectively as presented in fig 5. These results are considerably low compared to the AME results ranging between $68530 \& 90300 \mathrm{Kg} / \mathrm{cm}^{2}$.

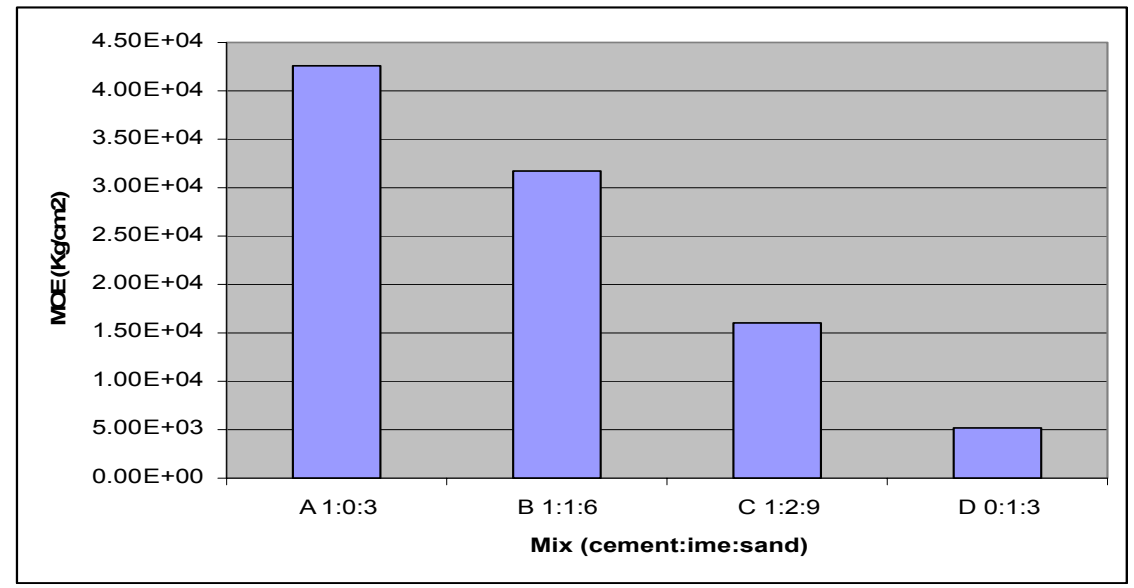

Figure 5: Average results of MOE.

\subsection{Conclusions and recommendations}

As there are enormous environmental benefits to straw bale construction in Egypt, this study is considered a preliminary step on the path of structural testing of plaster, one of the fundamental elements in this construction. The study showed that by increasing the lime content for the same cement content in the mix the compression strength and the modulus of rupture decreases dramatically for all mixes cured after 28 days in water tanks. The results of this study were not in favour with those results presented by the AME study that used low quality lime for the same mix proportions, which was cured after several ages. Other group of tests might show different importance for the lime content in the mix. It is therefore postponed by the research team to recommend the most appropriate cement plaster mix to be applied on the straw bale walls until applying all the required structural tests on the basic group of mixes under study. Also applying the same series of tests on earth plaster mixes is highly recommended in a further step of the project.

\section{References}

[1] Straube, J., Moisture Properties of Plaster and Stucco for Straw bale Buildings. Research Highlights-Technical Series-issue 00-132

[2] Lerner, K. and Donahue, K., Structural Testing of Plasters For Straw Bale Construction December 8, 2003 
[3] Zhang, J., Load-Carrying Characteristics of a Single Straw Bale Under Compression. University of Western Sydney, July 2000

[4] Mar, D., Bearing Test of plastered Straw Bales. Ecological Building Network, 2003. www.ecobuildnetwork.org

[5] Dreger, D., Compression Resistance of a Stuccoed Straw bale Wall, 2002

[6] University of Manitoba, Winnepeg, Manitoba 